\title{
ESTUDO IN VITRO DA EFICÁCIA DE CITRONELA (Cymbopogon wynterianus) SOBRE CARRAPATO Rhipicephalus (Boophilus) microplus
}

\author{
SANTOS, Tânia Regina Bettin dos ${ }^{1}$; \\ CASTRO, Natália Ávila de ${ }^{2}$; \\ BRETANHA, Lizandra Czermainski ${ }^{3}$; \\ SCHUCH, Luiz Filipe Damé ${ }^{1}$; \\ FREITAG, Rogério Antônio ${ }^{4}$; \\ NIZOLI, Leandro Quintana ${ }^{1}$.
}

Recebido: $21 / 11 / 2014$

Aceito: 08/01/2015

${ }^{1}$ Professor, Doutor, Departamento de Veterinária Preventiva, Faculdade de Veterinária - UFPEL; ${ }^{2}$ Médica Veterinária, Mestranda, Programa de Desenvolvimento Regional e Meio Ambiente - UNIR; ${ }^{3}$ Doutoranda, Programa de Pós-Graduação, UFSC; ${ }^{4}$ Professor, Doutor, Departamento de Química, Instituto de Química - UFPEL.

\section{RESUMO}

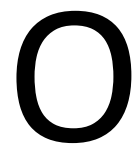

objetivo deste estudo foi avaliar o efeito in vitro do extrato aquoso, extrato hidroalcoólico, extrato hidroalcoólico concentrado e óleo essencial de citronela (Cymbopogon wynterianus) sobre larvas e teleóginas de Riphicephalus (Boophilus) microplus. Os extratos foram preparados de folhas secas de citronela. Para realizar os testes com as larvas foram utilizadas seis concentrações $(3,12 ; 6,25 ; 12,5 ; 25 ; 50$ e $100 \%)$ de cada extrato, além dos grupos controle. A sensibilidade das teleóginas aos extratos foi testada utilizando o Teste de Drummond (biocarrapaticidograma), sendo utilizados no teste: extrato aquoso a $100 \%$, extrato hidroalcoólico a $100 \%$, extrato hidroalcoólico concentrado a $50 \%$ e óleo essencial nas concentrações de 6,$25 ; 12,5$ e $25 \%$. As teleóginas também foram testadas frente a três produtos comerciais disponíveis no mercado. Os resultados indicaram que a citronela tem ação acaricida, principalmente, quando utilizada na forma de óleo essencial, pois a partir da concentração de $12,5 \%$ foi capaz de causar $100 \%$ de mortalidade larval, e a $25 \%$ demonstrou índice de eficácia de $100 \%$ no teste com teleóginas, resultado superior ao observado com os produtos comerciais testados. Conclui-se que citronela, na forma de óleo essencial, foi eficaz no controle de Riphicephalus (Boophilus) microplus nas condições deste experimento.

Palavras-chave: Fitoterapia. Acaricida. Controle do carrapato bovino. 


\section{INTRODUÇÃO}

O carrapato bovino Rhipichephalus (Boophilus) microplus é uma das cinco espécies do gênero, sendo a mais difundida e a única encontrada no Brasil. Essa espécie de artrópode possui ampla distribuição mundial, ocorrendo entre os paralelos $32^{\circ} \mathrm{N}$ e $32^{\circ} \mathrm{S}$. R. (B.) microplus tem destacada importância nos países da América Latina, África e Oceania. No Brasil, esse carrapato foi introduzido com o gado bovino trazido pelos primeiros colonizadores e atualmente encontra-se distribuído em todos os estados brasileiros (GUIMARÃES et al., 2001).

As principais perdas econômicas causadas pelo carrapato são diminuição na produção de carne e de leite; morte do animal, devido à transmissão de patógenos (GONZALES, 2003; MARTINS, 2006), e lesões na pele dos animais, que favorecem o aparecimento de infecções secundárias como miíases cutâneas, resultando na depreciação do couro. Além dessas perdas, somam-se gastos com tratamentos químicos, que embora tenham se mostrado efetivos no controle dos parasitos, favorecem o desenvolvimento de populações resistentes (FURLONG, 2004).

No Rio Grande do Sul, estima-se que os produtores perdem cerca de 70 milhões de dólares anualmente, somente considerando a produção de carne. Os gastos com agroquímicos para o controle e profilaxia do carrapato e de míases podem ultrapassar 190 milhões de dólares por ano. No Brasil, o prejuízo anual do parasitismo do $R$. (B.) microplus pode alcançar 1,8 bilhões de dólares/ano (CORDOVÉS, 1999; GRISI, et. al., 2002; VERÍSSIMO, 1993).

Atualmente, o fator relevante é o desenvolvimento da resistência dos carrapatos aos acaricidas; fato causado, tanto pelo uso constante dos carrapaticidas, como pelo manejo incorreto no controle do carrapato, que muitas vezes não leva em consideração sua epidemiologia. O controle estratégico aumentaria a eficiência e a vida útil dos produtos (FARIAS et al., 2008; ROCHA et al., 2006; SANTOS et al., 2009).

Outras questões preocupantes são a possibilidade dos produtos convencionais deixarem resíduos no leite e na carne, assim como contaminarem o solo, acarretando o extermínio de outros ácaros não parasitos. Esses fatores são de grande relevância na atualidade, em que alimentos mais saudáveis e práticas que reduzam os impactos ambientais são muito 
valorizadas pelo consumidor. Ademais, pesquisas demonstram a intoxicação de animais submetidos a consecutivos banhos com acaricidas químicos que, somados ao estresse físico do tratamento, predispõem os bovinos a outras enfermidades (CLARK; SÁNCHEZ, 1982).

Dentro desse contexto, a fitoterapia surge como alternativa por minimizar o desenvolvimento de resistência pelos carrapatos, além de ser biodegradável, não poluente, e possuir menor poder residual (CHAGAS et al., 2002).

Dentre as plantas com propriedades fitoterápicas, destaca-se a citronela (Cymbopogon wynterianus), cuja eficácia tem sido descrita na literatura como inibidora de fungos (DIKSHIT; HUSAIN, 1984; SARBHOY, 1978) e de nematódeos (SANGWIN, 1985), além da comprovada eficiência no controle de insetos, como a mosca-do-chifre (ALVES-BRANCO, 2000). Além disso, alguns estudos comprovam a atividade acaricida desta planta sobre $R$. (B.) microplus (MARTINS, 2006; OLIVO et al. 2008).

Dessa forma, o objetivo do presente estudo foi avaliar a ação da citronela, em diferentes extratos e concentrações, sobre larvas e teleóginas de $R$. (B.) microplus através de experimentação in vitro.

\section{MATERIAL E MÉTODOS}

\section{Obtenção dos extratos de citronela}

As partes aéreas da citronela (C. wynterianus) foram coletadas em uma propriedade no município de Capão do Leão, Rio Grande do Sul. As extrações foram realizadas no Laboratório de Fitoquímica do Instituto de Química da UFPEL, onde as partes coletadas foram secas em estufa de circulação de ar por 72 horas a $37^{\circ} \mathrm{C}$.

O extrato aquoso foi obtido através da infusão de $10 \mathrm{~g}$ de planta seca em $150 \mathrm{~mL}$ de água destilada a temperatura de 65 a $70{ }^{\circ} \mathrm{C}$ por 1 hora.

O extrato hidroalcoólico foi obtido a partir de $50 \mathrm{~g}$ de citronela seca em $500 \mathrm{~mL}$ de uma solução de etanol/água (90\%). A mistura ficou em Banho Maria de óleo por sete dias e agitação constante (40 ciclos por minuto) a uma temperatura de $37^{\circ} \mathrm{C}$. Após esse período foi 
separado $100 \mathrm{~mL}$ do extrato hidroalcoólico, e o restante da mistura foi colocado em evaporador rotativo para a retirada do álcool, e desta forma obter o extrato hidroalcoólico concentrado.

Para a obtenção do óleo essencial, $70 \mathrm{~g}$ da planta foram misturados em $1500 \mathrm{~mL}$ de água Milli-Q, e submetidos a quatro extrações utilizando-se aparelho de Clevenger, com tempo de refluxo de cinco horas. O produto final foi separado da água e seco com sulfato de sódio anidro.

Foi realizada análise cromatográfica do extrato oleoso para identificação dos constituintes químicos.

\section{Teste com larvas}

Para a obtenção de larvas de $R$. (B.) microplus, teleóginas de mais de 10 bovinos, de uma propriedade rural do município de Piratini, Rio Grande do Sul, naturalmente infestados, que não haviam recebido tratamento acaricida há mais de 30 dias, foram coletadas e encaminhadas para o Laboratório de Doenças Parasitárias da Faculdade de Veterinária da UFPEL. No laboratório, as teleóginas foram lavadas e colocadas em placas de Petri, sendo incubadas em estufa B.O.D. a $27{ }^{\circ} \mathrm{C}$ com umidade relativa $>70 \%$ para ovipostura. No 15 o dia de postura, os ovos foram transferidos para tubos de ensaio para eclosão larval. Larvas entre 10 e 20 dias de vida foram submetidas, em duplicata, ao teste de imersão de larvas, segundo a metodologia descrita por Sabatini et al. (2001), modificada para microtubo tipo Eppendorf ${ }^{\circledR}$, sendo imersas por cinco minutos, nas concentrações de 0,0; 3,12; 6,25; 12,5; 25; 50 e 100\% em cada tipo de extrato (aquoso, hidroalcoólico, hidroalcoólico concentrado e óleo essencial). Nos controles, as larvas foram submetidas aos diluentes dos respectivos extratos (água ou álcool).

Após a imersão, as larvas foram removidas com o auxilio de pincel com cerdas macias em alíquotas de 100 indivíduos. As larvas foram secas com o auxílio de papel absorvente e colocadas em envelopes de papel filtro. Os envelopes foram fechados e acondicionados em potes plásticos identificados de acordo com a concentração e o extrato utilizado. As larvas 
foram incubadas em estufa B.O.D. a $27{ }^{\circ} \mathrm{C}\left( \pm 1{ }^{\circ} \mathrm{C}\right)$ com umidade relativa superior a $75 \%$, durante 24 horas. Posteriormente, as larvas foram observadas, contadas e calculados os percentuais de mortalidade e média aritmética dos resultados obtidos nas duplicadas.

\section{Teste com teleóginas}

Teleóginas de $R$. (B.) microplus foram lavadas e secas em papel absorvente e dividas em grupos de dez indivíduos, com peso médio de 2,42 g $( \pm 0,02)$. As teleóginas foram submetidas ao biocarrapaticidograma, Teste de Drummond modificado (DRUMMOND et al., 1973), no Laboratório de Doenças Parasitárias da Faculdade de Veterinária (UFPEL). O extrato aquoso e o extrato hidroalcoólico foram testados a $100 \%$ de concentração. O extrato hidroalcoólico concentrado foi diluído em álcool etílico a 50\%, assim como o óleo essencial, que foi diluído a $6,25,12,5$ e $25 \%$. Além disso, foram utilizados grupos controles imersos em água e em álcool etílico de acordo com o diluente dos extratos, sendo que todos os grupos foram testados em duplicata.

As teleóginas também foram submetidas ao Teste de Drummond modificado, com produtos comerciais, sendo utilizadas formulações à base de amitraz, cipermetrina, e associação de cipermetrina + clorpirifós + citronelal, na diluição recomendada pelo Laboratório fabricante de cada fármaco.

\section{Análise Estatística}

A análise estatística foi realizada com o auxilio do programa Statistix 9.0. A análise dos resultados dos testes com larvas foi avaliada pelo Teste do Qui-quadrado. A avaliação dos testes com teleóginas foi realizada pela Análise de Variância e comparação de médias com um controle pelo método de Dunnet. Foram utilizados como controle, os produtos comerciais.

Os índices de eficácia reprodutiva (IR) e da eficácia (IE) foram calculados a partir das seguintes fórmulas: 
$I R=\underline{\text { Massa de ovos X \% de eclosão X } 20.000}$

Massa das fêmeas ingurgitadas

$$
I E=\underline{(I R \text { controle }-I R \text { tratado }) \times 100}
$$

IR controle

\section{RESULTADOS E DISCUSSÃO}

A análise cromatográfica do óleo essencial da citronela demonstrou a presença dos monoterpenos: geraniol e citronelal, resultados também encontrados por Martins (2006) e Torres (2010). O citronelal tem comprovada ação inseticida e acaricida (CHAGAS et al., 2002), e é utilizado pela indústria, associado a outros princípios ativos.

Martins (2006) estudou separadamente o citronelal, o geraniol e o citronelol, presentes no óleo essencial da citronela, e demonstrou a ação acaricida superior dos dois primeiros sobre o citronelol.

O efeito acaricida de diferentes concentrações e extratos de citronela em testes in vitro em larvas de $R$. (B.) microplus, realizados no presente estudo estão demonstrados na Tabela 1. 
Tabela 1 - Médias percentuais de mortalidade de larvas de $R$. (B.) microplus submetidas ao teste de imersão em diferentes concentrações e extratos de $C$. winterianus, Pelotas, RS, 2014.

Mortalidade (\%)

\begin{tabular}{ccccc}
$\begin{array}{c}\text { Concentração }(\%) / \\
\text { Tipo de extrato }\end{array}$ & Aquoso & Hidroalcoólico & $\begin{array}{c}\text { Hidroalcoólico } \\
\text { Conc. }\end{array}$ & Óleo \\
\hline 0 & 0 & $0^{a}$ & $0^{a}$ & $0^{a}$ \\
3,12 & 2 & $4^{a}$ & $28^{b}$ & $94^{b}$ \\
6,25 & 8 & $1^{a}$ & $32^{b}$ & $98^{c}$ \\
12,5 & 3 & $5^{a}$ & $39^{b}$ & $100^{c}$ \\
25 & 5 & $74^{b}$ & $99^{c}$ & $100^{c}$ \\
50 & 2 & $79^{b}$ & $100^{c}$ & $100^{c}$ \\
100 & 3 & $83^{b}$ & $100^{c}$ & $100^{c}$
\end{tabular}

Letras diferentes nas colunas indicam diferença estatística $(\mathrm{P}<0,05)$

A análise estatística não foi aplicada sobre os resultados no extrato aquoso, pois a variabilidade do percentual de mortalidade foi oscilante e na concentração de $100 \%$ foi capaz de matar somente $3 \%$ das larvas (Tabela 1 ). Isto ocorreu provavelmente porque os princípios ativos desse fitoterápico não são extraídos pela água, o que limita o uso deste tipo de extrato pelos pequenos produtores, apesar de ser um método mais simples e menos oneroso.

A análise estatística foi realizada entre as diferentes concentrações de um mesmo extrato, mas não entre os diferentes extratos. Desta forma, pode ser observado que no extrato hidroalcoólico concentrado, o grupo controle, difere estatisticamente dos resultados encontrados nas concentrações de 3,12, 6,25 e 12,5\%; e dos resultados obtidos nas concentrações de 25, 50 e 100\%, indicando um aumento da mortalidade larval, com o aumento da concentração do extrato (Tabela 1). 
Os resultados obtidos demonstram que o extrato hidroalcoólico concentrado e o óleo essencial extraídos de citronela são promissores para o controle de carrapato $R$. (B.) microplus, concordando com Martins (2006), o qual demonstrou em seu estudo, mortalidade de $100 \%$ das larvas quando submetidas à imersão no óleo essencial a uma concentração de 5,55\% e com Olivo et al. (2008) que comprovaram eficácia superior a 92\% do óleo essencial de citronela em concentração de $1 \%$.

Os resultados de diferentes extratos de citronela ( $C$. winterianus) e de formulações comerciais, sobre teleóginas de $R$. (B.) microplus, estão demonstrados na Tabela 2.

Tabela 2. Resultados de diferentes concentrações e extratos de $C$. winterianus e de três acaricidas comerciais sobre parâmetros biológicos de teleóginas de $R$. (B.) microplus após tratamento por imersão ${ }^{1}$ de teleóginas, Pelotas, RS, 2014.

\section{Parâmetros Biológicos}

\section{Extratos e concentrações}

(\%)

\section{Mortalidade}

(\%)

\section{Massa de}

ovos (g)
Eclodibilidade

(\%)
Índice de Eficácia

(\%)

\begin{tabular}{lcccc}
\hline Controle Água & 15 & 1,244 & 100 & -- \\
Controle Álcool & 15 & 1,132 & 100 & -- \\
Aquoso 100 & $20^{\mathrm{abc}}$ & $1,073^{\mathrm{bc}}$ & $100^{\mathrm{bc}}$ & $10^{\mathrm{bc}}$ \\
$\begin{array}{llll}\text { Hidroalcoólico } 100 \\
\text { Hidroalcoólico }\end{array}$ & $15^{\mathrm{bc}}$ & $1,649^{\mathrm{bc}}$ & $80^{\mathrm{c}}$ & 63 \\
$\begin{array}{l}\text { concentrado 50 } \\
\text { Óleo essencial 6,25 }\end{array}$ & $65^{\mathrm{ab}}$ & $0,405^{\mathrm{a}}$ & $95^{\mathrm{bc}}$ & $80^{\mathrm{a}}$ \\
Óleo essencial 12,5 & $60^{\mathrm{ab}}$ & $0,230^{\mathrm{b}}$ & $35^{\mathrm{a}}$ & $91^{\mathrm{a}}$ \\
Óleo essencial 25 & $65^{\mathrm{ab}}$ & $0,259^{\mathrm{a}}$ & $22^{\mathrm{a}}$ & $100^{\mathrm{a}}$ \\
Amitraz & $90^{\mathrm{a}}$ & $0,048^{\mathrm{a}}$ & $5^{\mathrm{a}}$ & $0^{\mathrm{c}}$ \\
Cipermetrina & $10^{\mathrm{abc}}$ & $1,292^{\mathrm{c}}$ & $88^{\mathrm{c}}$ & $11^{\mathrm{b}}$ \\
Ciper+clorpirifós+citronelal & $30^{\mathrm{ab}}$ & $1,051^{\mathrm{b}}$ & $95^{\mathrm{b}}$ & $93^{\mathrm{a}}$ \\
\hline
\end{tabular}

1. Teste de Drummond et al., 1973, modificado.

Letras diferentes nas colunas indicam diferença estatística $(P<0,05)$. 
O Teste de Drummond modificado demonstrou que o extrato aquoso foi pouco eficaz sobre as teleóginas ingurgitadas de $R$. (B.) microplus, (Tabela 2), possivelmente pelo mesmo motivo de seu fraco desempenho no teste com as larvas (Tabela 1).

O extrato hidroalcoólico a 100\% demonstrou um índice de eficácia de 10\%, sugerindo que o álcool não foi capaz de extrair e/ou reter o princípio ativo do fitoterápico. Baixos índices de eficácia em extrato hidroalcoólico de citronela foram relatados por Broglio-Micheletti et al. (2009) que demonstraram eficácia de apenas 18,35\%, utilizando o Teste de Drummond com extrato hidroalcoólico de $C$. citratus a $2 \%$.

Os resultados do uso de óleo essencial da citronela (Tabela 2) demonstraram que a mortalidade foi crescente de acordo com o aumento da concentração, variando entre 60 e $90 \%$, enquanto que o percentual de eclodibilidade teve uma relação inversa à concentração. O melhor efeito acaricida da citronela foi observado com o óleo essencial, provavelmente porque o princípio ativo citronelal fica retido principalmente na porção oleosa da planta. A eficácia do óleo de citronela sobre $R$. (B.) microplus, já foi descrita por Martins (2006) e Olivo et al. (2008).

A eficácia desse fitoterápico já foi descrita também por Chungsamarnyart e Jiwajinda (1992) que, ao utilizarem o óleo de citronela a 12,5; 8,3 e 7,1\% diluído em etanol, verificaram ação larvicida de 95,7; 92,7 e 58,1\%, respectivamente. Ao avaliarem óleo de $C$. winterianus, estes autores demonstraram eficiência de $50 \%$ no controle de teleóginas e larvas, nas concentrações de 6,1 e 4,1\%, respectivamente.

De acordo com os dados apresentados na Tabela 2, o índice de eficácia do produto comercial a base de amitraz foi de $0 \%$, sugerindo que a população de carrapato estudada apresenta resistência a esse princípio ativo, conforme já descrito na região sul do Rio Grande do Sul por Farias et al. (2008) e Santos et al. (2008). A população de teleóginas testadas também demonstrou resistência à cipermetrina, confirmando os dados descritos por Farias et al. (2008). No entanto, em teste com produto com associação de cipermetrina + clorpirifós + citroneal a 1\% (princípio ativo da citronela), os autores observaram eficácia superior a $90 \%$. 
De acordo com a análise estatística (Tabela 2), os resultados do óleo essencial de citronela nas concentrações de 6,$25 ; 12,5$ e $25 \%$ não diferiram do controle positivo (produto comercial a base de cipermetrina + clorpirifós + citronelal) em relação à eclodibilidade e índice de eficácia, indicando que este extrato é eficaz como acaricida. Em comparação com o controle negativo (Cipermetrina) verificou-se que a mortalidade difere estatisticamente somente na concentração de $25 \%$ (Tabela 2).

O índice de eficácia, do extrato aquoso a $100 \%$ e o extrato hidroalcoólico de citronela a $100 \%$, não demonstraram diferença estatística significativa em relação ao controle negativo, não sendo eficaz para o controle de teleóginas dessa população de carrapatos, o que já havia sido observado no teste com larvas (Tabela 1).

Considerando a análise dos dados em relação ao amitraz (controle negativo), observou-se que o extrato aquoso $100 \%$ e o extrato hidroalcoólico de citronela $100 \%$, apresentaram os parâmetros biológicos (percentuais de mortalidade, massa de ovos, eclodibilidade e índice de eficácia), estatisticamente significativos $(p<0,05)$ (Tabela 2). Portanto, ineficazes para o controle desse ectoparasita, assim como, demonstrou-se o amitraz (Índice de Eficácia =0).

Como demonstrado na Tabela 2, o tratamento com extrato hidroalcoólico concentrado a $50 \%$ gerou uma produção de massa de ovos similar ao controle positivo, estatisticamente significativo, entretanto, o índice de eficácia de 63\% não apresentou significância estatística nem com o controle positivo, nem com os negativos.

O óleo essencial de citronela a 3,12\% foi capaz de matar $94 \%$ das larvas (Tabela 1) e no dobro dessa concentração $(6,25 \%)$ matou $80 \%$ das teleóginas (Tabela 2), provavelmente pelo fato das fêmeas adultas serem naturalmente mais resistentes aos produtos que agem por contato, e as larvas além de possuírem respiração cutânea, possuem a cutícula menos espessa.

Em ambos os experimentos (Tabelas 1 e 2) foi observada uma correlação positiva entre concentração e índice de eficácia dos produtos, entretanto, o óleo essencial apresentou eficiência significativamente maior que as demais formas de extração. Além disso, os resultados da eficácia sobre as larvas são mais promissores, confirmando que o tratamento preventivo desse ectoparasito, quando as fases parasitárias presentes são larvas e ninfas, é a 
melhor estratégia de controle, pois além dessas fases serem mais sensíveis, a espoliação nos bovinos causada por esses estágios é pequena, em relação ao volume sanguíneo ingerido por teleóginas (GONZALES, 2003; SANTOS et al. 2009).

De acordo com os resultados obtidos no presente estudo, o óleo essencial apresentou resultados promissores, atingindo-se mortalidade de 60, 65 e 90\% nas concentrações de $6,25,12,5$ e $25 \%$, respectivamente, reafirmando o que já foi descrito por outros autores (CHUNGSAMARNYART; JIWAJINDA, 1992; MARTINS, 2006; MARTINS; GONZALEZ, 2007; OLIVO et al., 2008) que demonstraram a eficácia acaricida do óleo essencial da citronela com índices de eficácia superiores em concentrações menores dos que as utilizadas nesse estudo. O efeito acaricida descrito por Martins (2006) demonstrou eficácia de 100\% sobre teleóginas ao utilizar o extrato oleoso da citronela à concentração de 10\%. Em 2007, Martins e Gonzalez trabalhando com o óleo essencial de $C$. winterianus in vivo, aplicado puro na linha dorsal do bovino e por aspersão na proporção de 1:10 diluído em álcool, observaram que ambos os tratamentos foram eficazes para o controle do carrapato bovino, não demonstrando toxicidade aos animais.

\section{CONCLUSÃO}

Os resultados apresentados demonstram que o extrato aquoso de citronela, não tem efeito acaricida. Entretanto, o extrato hidroalcoólico concentrado e o óleo da citronela ( $C$. winterianus) apresentaram efeito acaricida sobre larvas e teleóginas da população de $R$. (B.) microplus testada. O óleo essencial de $C$. winterianus possui geraniol e citronelal princípios ativos com ação acaricida.

Conclui-se ainda, que o óleo essencial de citronela demonstrou eficiência significativa como acaricida podendo ser intensificada a sua utilização como alternativa de controle de $R$. (B.) microplus. 


\title{
IN VITRO STUDY OF THE EFFECTIVENESS OF CITRONELLA (Cymbopogon wynterianus) ON THE CATTLE TICK Rhipicephalus (Boophilus) microplus
}

\begin{abstract}
$\mathrm{T}$ he objective of this study was to evaluate the in vitro effect of Cymbopogon wynterianus (citronella) aqueous extract, hydroalcoholic extract, concentrated hydroalcoholic extract and essential oil on larvae and engorged females of Riphicephalus (Boophilus) microplus. The extracts were obtained from dried leaves of citronella. To perform the tests with larvae six concentrations were used $(3.12,6.25,12.5$, 25, 50 and 100\%) of each extract, and the control groups. To perform the tests with engorged female ticks aqueous extract, simple alcoholic extract at a concentration of $100 \%$, concentrated hydroalcoholic extract $50 \%$ and oil extract in the concentrations of $6.25,12.5$ and $25 \%$ were used. Engorged females were also tested by Drummond's method against commercial products available on the market. The results indicated that citronella has acaricide action, especially when used as an essential oil, since the concentration of $12,5 \%$ caused $100 \%$ of larval mortality. The tests with engorged females demonstrated $100 \%$ of efficacy in the concentration of $25 \%$. These results were better than those observed with the commercial products. We conclude that essential oil of citronella is an effective alternative to control Riphicephalus (Boophilus) microplus under the conditions of this experiment.
\end{abstract}

Keywords: Phytotherapy. Acaricide. Cattle tick control.

\section{ESTUDIO IN VITRO DE LA EFICACIA DE CITRONELLA (Cymbopogon wynterianus) SOBRE Rhipicephalus (Boophilus) microplus}

\section{RESUMEN}

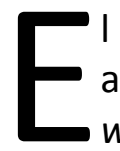

objetivo de este estudio fue evaluar el efecto in vitro del extracto acuoso, extracto alcohólico, concentrado extracto alcohólico y aceite esencial de Cymbopogon wynterianus (citronela) en larvas y garrapatas de Riphicephalus (Boophilus) microplus. Los extractos se obtienen a partir de hojas secas de citronela. Para realizar las pruebas con larvas se utilizaron seis concentraciones $(3,12,6,25,12,5,25,50$ y $100 \%)$ de cada extracto además de los grupos de control. Para probar se utilizaron las garrapatas: extracto acuoso $100 \%$, de extracto hidroalcohólico $100 \%$, de extracto hidroalcohólico concentró hasta $50 \%$ y el aceite esencial en concentraciones de 6,$25 ; 12,5$ y $25 \%$. Las garrapatas también se testearon frente a tres productos comerciales disponibles en el mercado. Los resultados indicaron que la citronela tiene acción acaricida, especialmente cuando se utiliza en forma de aceite esencial, ya que como la concentración de $12,5 \%$ fue capaz de causar $100 \%$ de mortalidad de las larvas, y demostró $25 \%$ de tasa de eficacia $100 \%$ en el ensayo con 
garrapatas, mayor que la observada con los productos comerciales probados. En conclusión, citronela, en forma de aceite esencial fue eficaz en el control de Riphicephalus (Boophilus) microplus en este experimento.

Palabras clave: Fitoterapia. Acaricida. Control de la garrapata del bovino.

\section{REFERÊNCIAS}

ALVES-BRANCO, F. P. J. Atividade de repelência do extrato de Citronela nas infestações por Haematobia irritans em bovinos. In: SEMINÁRIO BRASILEIRO DE PARASITOLOGIA VETERINÁRIA, 11, 2000, Salvador. Resumos. Salvador, 2000. 123p.

BROGLIO-MICHELETTI, S. M. F.; VALENTE, E. C. N.; SOUZA, L. A.; et al. Extratos de plantas no controle de Rhipicephalus (Boophilus) microplus (Canestrini, 1887) (Acari:Ixodidae) em laboratório. Revista Brasileira de Parasitologia Veterinária, v. 18, n. 4, p. 44-48, 2009.

CHAGAS, A. C. S.; PASSOS, W. M.; PRATES, H. T.; et al. Efeito acaricida de óleos essenciais e concentrados emulsionáveis de Eucalyptus spp. em Boophilus microplus. Brazilian Journal of Veterinary Research and Animal Science, v. 39, n. 5, p. 247-253, 2002.

CHUNGSAMARNYART, N.; JIWAJINDA, S. Acaricidal activity of volatile oil from lemon and citronella grasses on tropical cattle ticks. Kasetsart Journal, v. 26, p. 46-51, 1992.

CLARK, L. G.; SANCHEZ, S. J. Association of pesticide toxicosis with some health factors during the tick eradication program in Puerto Rico. In: INTERNATIONAL SYMPOSIUM ON VETERINARY EPIDEMIOLOGY AND ECONOMICS, 3, 1982, Arlington. Proceedings.

Edwardsville: Veterinary Medicine Puslishing Co., p. 620-623, 1982.

CORDOVÉS, C. O. Carrapatos: controle e erradicação. Alegrete: Gralha, 1999. 130p.

DIKSHIT, A.; HUSAIN, A. Antifungal action of some essential oils against animal pathogens. Fitoterapia, v. 55, n. 3, p. 171-176, 1984.

DRUMMOND, R. O.; ERNEST, S. E.; TREVINO, J. L.; et al. Boophilus annulatus and Boophilus microplus. Laboratory tests of insecticides. Journal of Economic Entomology, v. 66, n. 1, p. 130-133, 1973.

FARIAS, N. A.; RUAS, J. L.; SANTOS, T. R. B. Análise da eficácia de acaricidas sobre o carrapato Boophilus microplus, durante a última década, na região Sul do Rio Grande do Sul. Ciência Rural, v. 38, n. 6, p. 1700-1704, 2008.

FURLONG, J. Controle estratégico do carrapato dos bovinos. A Hora Veterinária, v. 23, n. 137, p. 53-56, 2004. 
GONZALES, J. C. O controle do carrapato do boi. 2. ed. Porto Alegre: Ética, 2003. 80p.

GRISI, L.; MASSARD, C. L.; MOVA BORJA, G. E.; et al. Impacto econômico das principais ectoparasitoses em bovinos no Brasil. A Hora Veterinária, v. 21, n. 125, p. 8-10, 2002.

GUIMARÃES, J. H.; TUCCI, E. C.; BARROS-BATTESTI, D. M. Ectoparasitos de importância veterinária. São Paulo: Plêiade, 2001. 318p.

MARTINS, R. M. Estudo in vitro da ação acaricida do óleo essencial da gramínea Citronela de Java (Cymbopogon winterianus Jowitt) no carrapato Boophilus microplus. Revista Brasileira de Plantas Medicinais, v. 8, n. 2, p. 71-78, 2006.

MARTINS, R. M.; GONZÁLEZ, F. H. D. Uso del aceite de citronela de Java (Cymbopogon winterianus Jowitt) (Panicoidideae) como acaricida frente a la garrapata Boophilus microplus Canestrini (Acari: Ixodidae). Revista Brasileira de Plantas Medicinais, v. 9, n. 4, p. 1-8, 2007.

OLIVO, C. J.; CARVALHO, N. M.; SILVA, J. H. S.; et al. Óleo de citronela no controle do carrapato de bovinos. Ciência Rural, v. 38, n. 2, p. 406-410, 2008.

ROCHA, C. M. B. M.; OLIVEIRA, P. R.; LEITE, R. C.; et al. Percepção dos produtores de leite do município de Passos, MG, sobre o carrapato Boophilus microplus (Acari: Ixodidae), 2001.

Ciência Rural, v. 36, n. 4, p. 1235-1242, 2006.

SABATINI, G. A; KEMP, D. H; HUGHES, S.; NARI, A.; HANSEN, J. Tests to determine LC50 and discriminating doses for macrocyclic lactones against the cattle tick, Boophilus microplus.

Veterinary Parasitology, v. 95, n. 1, p. 53-62, 2001.

SANGWIN, N. K. Nematicidal activity of essential oils of Cymbopogon grasses. Nematológica, v. 31, n. 1, p. 93-99, 1985.

SANTOS, T. R. B.; FARIAS, N. A. R.; CUNHA FILHO, N. A.; et. al. Uso de acaricidas em Rhipicephalus (B.) microplus de duas regiões fisiográficas do Rio Grande do Sul. Acta Scientiae Veterinarie, v. 36, n. 1, p. 25-30, 2008.

SANTOS, T. R. B.; FARIAS, N. A. R.; CUNHA FILHO, N. A.; et. al. Abordagem sobre o controle do carrapato Rhipichephalus (Boophilus) microplus no sul do Rio Grande do Sul. Pesquisa Veterinária Brasileira, v. 29, n. 1, p. 65-79, 2009.

SARBHOY, A. K. Efficacy of some essential oils and their constituents on few ubiquitous molds. Zentralblatt fur Bakteriologie Naturwiss, v. 133, n. 7-8, p. 723-725, 1978.

TORRES, F. C. Avaliação da atividade acaricida das frações dos óleos essenciais de Citronela (Cymbopogum winterianus), Alecrim (Rosmarinus officinalis) e Aroeira (Schinus molle). Porto Alegre, PUC, 2010. Dissertação (Mestrado em Engenharia e Tecnologia de Materiais). Pontifícia Universidade Católica do Rio Grande do Sul, 2010, 69p. 
VERÍSSIMO, C. J. Controle do Carrapato dos Bovinos. Jaboticabal: FUNEP, 1993, 26p.

Autor para correspondência:

Tânia Regina Bettin dos Santos. Laboratório de Doenças Parasitárias, Faculdade de Veterinária, Campus Universitário, UFPEL.

Capão do Leão (RS).

trb.santos@hotmail.com 